\title{
PERFORMANCE OF THE ENHANCED VEGETATION INDEX TO DETECT INNER-ANNUAL DRY SEASON AND DROUGHT IMPACTS ON AMAZON FOREST CANOPIES
}

\author{
Benjamin Brede, Jan Verbesselt, Loïc P. Dutrieux, Martin Herold \\ Laboratory of Geo-Information Science and Remote Sensing, Wageningen University, \\ Droevendaalsesteeg 3, 6708PB, Wageningen, The Netherlands - \\ (Benjamin.Brede, Jan.Verbesselt, Loic.Dutrieux, Martin.Herold)@wur.nl
}

KEY WORDS: Amazon rainforests, Enhanced Vegetation Index, dry season leaf flush, sun-sensor geometry effects, drought impact

\begin{abstract}
:
The Amazon rainforests represent the largest connected forested area in the tropics and play an integral role in the global carbon cycle. In the last years the discussion about their phenology and response to drought has intensified. A recent study argued that seasonality in greenness expressed as Enhanced Vegetation Index (EVI) is an artifact of variations in sun-sensor geometry throughout the year. We aimed to reproduce these results with the Moderate-Resolution Imaging Spectroradiometer (MODIS) MCD43 product suite, which allows modeling the Bidirectional Reflectance Distribution Function (BRDF) and keeping sun-sensor geometry constant. The derived BRDF-adjusted EVI was spatially aggregated over large areas of central Amazon forests. The resulting time series of EVI spanning the 2000-2013 period contained distinct seasonal patterns with peak values at the onset of the dry season, but also followed the same pattern of sun geometry expressed as Solar Zenith Angle (SZA). Additionally, we assessed EVI's sensitivity to precipitation anomalies. For that we compared BRDF-adjusted EVI dry season anomalies to two drought indices (Maximum Cumulative Water Deficit, Standardized Precipitation Index). This analysis covered the whole of Amazonia and data from the years 2000 to 2013. The results showed no meaningful connection between EVI anomalies and drought. This is in contrast to other studies that investigate the drought impact on EVI and forest photosynthetic capacity. The results from both sub-analyses question the predictive power of EVI for large scale assessments of forest ecosystem functioning in Amazonia. Based on the presented results, we recommend a careful evaluation of the EVI for applications in tropical forests, including rigorous validation supported by ground plots.
\end{abstract}

\section{INTRODUCTION}

The Amazon rainforests represent the largest connected forested area in the tropics. They play an integral role in the global carbon cycle and store $\sim 93 \pm 23 \mathrm{Pg} \mathrm{C}$ in above-ground living biomass alone (Malhi et al., 2006). In recent years the discussion about their resilience against transition to other stable ecosystem states has become more intense. Climate change and deforestation put pressure on the forests (Malhi et al., 2008) and the question appeared if they may partly, but abruptly transform into savannahs (White et al., 1999; Cox et al., 2004; Hirota et al., 2010).

The discussion of drought impacts has been vivid in the past years partially due to the severe droughts in 2005 and 2010 and its implications. In a fast response survey Phillips et al. (2009) assessed the impact of the 2005 drought on tree biomass in longterm forest census plots and found major biomass losses, which ended a long-term trend in tree carbon assimilation. Phillips et al. (2010) refined this analysis. They found evidence for elevated mortality rates 2 years after the meteorological event. Furthermore, large trees had a disproportionately high mortality during the drought. This is supported by de Toledo et al. (2013).

On the other hand, Schwalm et al. (2010) found a positive response of Net Primary Productivity (NPP) to relative drought. Actually, some studies found higher rates of carbon uptake during the dry compared to the wet season (Saleska et al., 2003; Hutyra et al., 2007). Instead of precipitation regimes, carbon uptake was controlled by phenology and light conditions (Hutyra et al., 2007). This does not contradict the aforementioned studies. The idea would be that water shortage as it occurs regularly in dry seasons does not necessarily lead to water shortage for the trees as some

\footnotetext{
${ }^{*}$ Corresponding author
}

have access to soil water via deep roots (Nepstad et al., 1994). However, prolonged dryness depletes the soil water storage and eventually shows effects in tree health and carbon uptake. This means that regular dry seasons may first lead to increased carbon uptake, but the effect turns when the dry season turns into drought.

Besides ground plots, satellite remote sensing delivers information about spatial and temporal patterns of drought impacts. The dry season resilience was observed with optical remote sensing data and especially Moderate-Resolution Imaging Spectroradiometer (MODIS) Enhanced Vegetation Index (EVI). An increase in Enhanced Vegetation Index (EVI) during the dry months was explained with flushing of new leafs (Myneni et al., 2007; Samanta et al., 2012). This would be a combined effect of an increase in Leaf Area Index (LAI) and a change in leaf optical properties. However, other studies raise concern about sun and viewing geometry effects in EVI (Sims et al., 2011; Galvão et al., 2011; Moura et al., 2012). Galvão et al. (2011) studied a seasonal evergreen forest in the tropical forest savannah transition zone and found the highest EVI at the end of the dry season, when Solar Zenith Angle (SZA) was smallest. Morton et al. (2014) corrected MODIS EVI for sun and viewing geometry effects with the help of a kernel based Bidirectional Reflectance Distribution Function (BRDF) model for MODIS tiles h11v09 and h12v09, which are situated over the central parts of the Amazon rainforests. Analysis of this data showed no remaining seasonality.

The objective of this study was to use a data set independent from Morton et al. (2014), but with the same study area, and check the consistency of the results. Additionally, the intra-annual effect of dry season strength expressed with drought indices was investigated for the whole of the Amazon rainforests. 


\section{METHOD}

\subsection{Study Area}

We identified tropical forests in the Amazon basin with the MODIS MCD12Q1 Land Cover Type product V051 with $500 \mathrm{~m}$ spatial resolution. In order to focus on mostly undisturbed forests, we set the requirement for each pixel that at least two thirds of all land cover observations in the temporal domain have to be evergreen broadleaf forest according to the International GeosphereBiosphere Programme (IGBP) classification scheme. Additionally, only pixels within the hydrological Amazon river basin (Mayorga et al., 2012) were considered. The resulting landcover mask can be seen in Figure 1.

\subsection{Data}

A major aim of this study was to correct Bidirectional Reflectance Factors (BRFs) for sun sensor geometry effects. The MCD43 product suite provides unique opportunities for this purpose. It contains results of fitting pixel- and band-wise reflectance observations of 16 days to a semi-empirical BRDF model, the RossThickLiSparse-Reciprocal (RTLSR) model (Schaaf et al., 2002, 2011). This kernel based model describes the surface BRDF as the sum of isotropic, volumetric and geometric scattering. The volumetric kernel assumes a dense canopy of randomly oriented facets, while the geometric kernel is based on non-overlapping shadows cast by randomly distributed objects (Roujean et al., 1992; Strahler et al., 1999; Lucht et al., 2000). With the three parameters for the isotropic $f_{i s o}$, volumetric $f_{v o l}$ and geometric $f_{g e o}$ kernels BRFs at any given SZA and View Zenith Angle (VZA) can be modeled. The statistical fitting of the model to observations requires several measurements. Therefore, both Aqua and Terra MODIS instruments deliver input to the inversion process (Strahler et al., 1999; Lucht et al., 2000). A back-up algorithm offers model inversions when only few observations are available. This algorithm makes use of the BRDF properties of previous full inversions and scales these shapes to new measurements. This back-up algorithm is termed magnitude inversion.

For this study we downloaded MCD43A1 (inversion parameters), MCD43A2 (quality and auxiliary data) and MCD43A4 (BRFs modeled at nadir and local solar noon, Nadir BRDF-Adjusted Reflectance (NBAR) product) data from the MODIS data pool (https://lpdaac.usgs.gov/) from between February 18, 2000 and November 25, 2013 and spatial tiles with horizontal numbers 10 to 12 and vertical numbers 8 to 9 ( 9 tiles in total), which cover

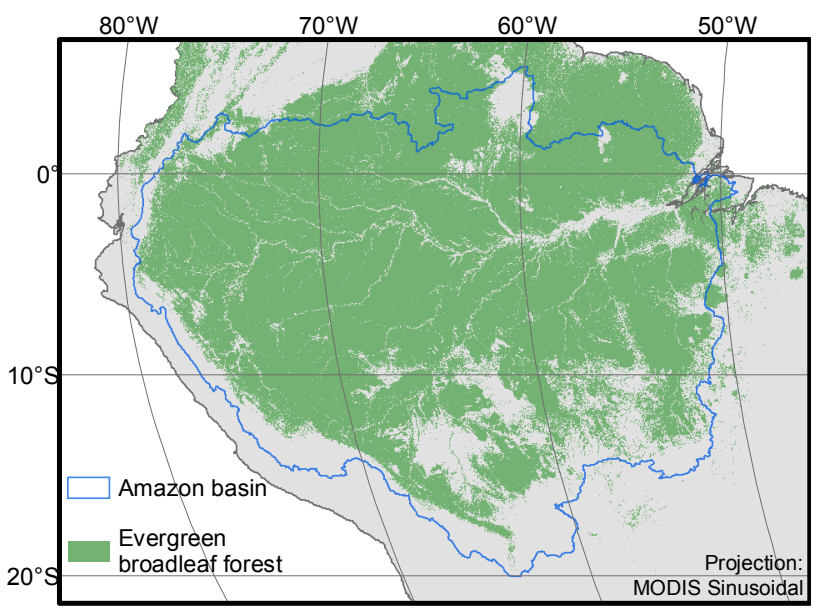

Figure 1: Study Area (land boundaries based on data set of Bjorn Sandvik www.thematicmapping.org). northern South America. The temporal resolution is quasi 8 daily, as the production is temporally overlapping.

For spatial analysis of precipitation we used the Tropical Rainfall Measuring Mission Multisatellite Precipitation Analysis (TMPA) 3B 42 V7 daily accumulated precipitation product at $0.25^{\circ}$ spatial resolution (Huffman et al., 2010). We downloaded data with the same time span as for the MODIS BRDF products.

\subsection{EVI Seasonality}

Based on the MCD43 products we produced 7 time series for the whole of the study period. These time series represent spatial averages over MODIS tiles h11v09 and h12v09. Morton et al. (2014) also focused on these two tiles. All products were filtered with the landcover information and with the MCD43A2 quality flags to allow only full BRDF inversions. The time series produced were:

- NBAR Near Infrared Reflectance (NIR) reflectance, Normalized Difference Vegetation Index (NDVI) and EVI;

- BRDF-adjusted NIR reflectance, NDVI and EVI modeled at $\mathrm{VZA}=0^{\circ}$ and $\mathrm{SZA}=30^{\circ}$;

- SZA at local solar noon.

The seasonal behavior of these time series were analyzed with a special focus on green-up phenomenon during the dry season as found by other studies (Huete et al., 2006; Xiao et al., 2006; Myneni et al., 2007; Samanta et al., 2012).

\subsection{Impact of Drought on EVI}

For the comparison of MODIS derived products with drought metrics based on TMPA the MODIS products were first spatially aggregated to the TMPA resolution of $0.25^{\circ}(\sim 30 \mathrm{~km}$ at equator $)$. For the landcover mask the requirement for a pixel to be valid in the aggregated map was that at least $90 \%$ of the underlying MODIS pixels were evergreen broadleaf forest. The MODIS reflectance products were quality filtered (only full inversions) and averaged. On the other hand, TMPA daily precipitation was temporally averaged to the quasi 8-day periods of the MCD43 products. In this way both datasets were synchronized to $0.25^{\circ}$ spatial and 8-day temporal resolution for the whole Amazon basin.

Based on the aggregated MODIS products we derived BRDFadjusted EVI standardized anomalies over the temporal domain, which means standardized anomalies per pixel time series. This is a useful approach as the anomaly describes the deviation of EVI in relation to its mean for each pixel. Furthermore, anomalies were derived only for data from Septembers. This is the last month in the Amazon dry season, commonly defined as July to September (Samanta et al., 2012). September should show highest impact of precipitation related impact on greenness. The TMPA was further processed to drought indices, namely Standardized Precipitation Index (SPI) (McKee et al., 1993) and Maximum Cumulative Water Deficit (MCWD) (Aragão et al., 2007). The SPI behaves similar as seasonal anomalies with values oscillating around 0 and deviations meaning more or less precipitation than usual. The MCWD assumes an evapotranspirational demand of $100 \mathrm{~mm} \mathrm{month}^{-1}$ of tropical forests and holds the available precipitation against this. Subsequent months with less precipitation than $100 \mathrm{~mm} \mathrm{month}^{-1}$ let the MCWD build up, which typically happens in the dry season.

The connection between greenness anomalies and drought was analyzed with pixel-based linear regression models, where September 
greenness anomaly was the dependent and the respective drought index the independent variable. Per $0.25^{\circ}$ pixel this produced slope estimates for the statistical relationship and how likely greenness was dependent on the drought index, i. e. its significance. These values were analyzed as maps. Additionally, the greenness anomaly-drought index pairs were analyzed on a MODIS tile basis. This means all greenness anomaly values were regressed against all drought index values per MODIS tile.

\section{RESULTS}

\subsection{EVI Seasonality}

Figure 2 shows spatially averaged BRFs and vegetation indices time series with 8 day temporal resolution, which emulate the results of Morton et al. (2014). From the start of the time line until circa 2002 occasional gaps appeared, when no data was available for the whole study area. Additional observations by Aqua MODIS after 2002 explain the fewer gaps. When considering the data density over time for the h11v09 and h12v09 tiles only very few observations during the wet season were available.

Another dependence was the one between SZA and NBAR NIR reflectance. As seen in Figure 2 NBAR NIR reflectance followed the SZA without a temporal lag. Even the two peaks around the turn of the year occurred in both time series. The SZA pattern marks the sun's apparent movement during the course of the year: The equinoxes occur on September 23 and March 20, and result in the lowest SZAs. A low Kendall's $\tau$ between SZA and NBAR NIR reflectance of -0.725 underlined this strong and reversed relationship. The SZA-NIR reflectance coupling was especially strong in the NBAR product, because it uses the SZA at local solar noon as an input for SZA in the RTLSR model.

On the other hand, this coupling was much weaker for the BRDFadjusted NIR reflectance and EVI. The double peak structure of SZA did not appear in all years for the BRDF-adjusted NIR reflectance. Additionally, the magnitude of change during austral summer was much lower compared to NBAR processed products. A relatively low Kendall's $\tau$ of -0.325 between BRDF-adjusted NIR reflectance and SZA underpinned this weaker coupling. An explanation for this is that the BRDF-adjusted NIR reflectance used a fixed SZA, so that a direct impact of the SZA on NIR reflectance should not be possible. Nonetheless, correlation between
BRDF-adjusted EVI and SZA showed mostly no lags and some years showed the double peak pattern observed in the NBAR EVI.

\subsection{Impact of Drought on EVI}

The map representations of pixel-based linear regression models of BRDF-adjusted EVI seasonal anomalies against MCWD showed distinct spatial patterns (Figure 3). Slope parameters close to 0 dominated eastern and southern Amazonia, indicating low predictive power of MCWD for EVI anomalies. North-western regions showed a mixture of both strong positive and negative slopes. This would indicate that EVI anomalies vary with MCWD, which indicates drought impact on canopy greenness. However, in most of these areas the regression slopes were not significant. After examining scatterplots for single pixels from these areas (graphs not shown), it was clear that these steep slopes were mostly produced by single MCWD outliers with magnitudes of up to $50 \mathrm{~mm}$. This is still much lower than MCWD values at the southern and eastern rainforest borders. Additionally, pairs with low MCWD values were mostly missing in these cases, possibly due to high cloud cover, which lead to missing EVI points. This combination led to randomly high or low slope values. The same was true for a strip along the foothills of the Andes at the western edge of the study area, where orographic cloud formation throughout the year hampers good quality observations.

The scatterplots for the tile-based approach showed the main characteristic of MCWD (Figure 4): Values clustered at a certain lower threshold. This is 0 for regions that did not experience notable dry seasons in terms of absolute water deficit (h11v09, h12v09). In tile h12v10 values only started at about $100 \mathrm{~mm}$ pointing to distinct dry seasons in this area. Independent from that, all point clouds were approximately equally distributed around the 0 EVI anomaly line. In all plots except h12v10 a point of high density towards the lower end of the MCWD axis was observed. Most regression models showed significant negative relationships of MCWD with EVI anomaly $(\mathrm{p}<0.001)$. However, most models explained less than $5 \%$ of the variance in EVI. This suggests that the linear models are not meaningful in this context.

The resulting maps for SPI showed different patterns than for MCWD (Figure 5). A cluster of positive responses could be found over western Amazonia. This implies that EVI was low during relative droughts, which means greenness sensitivity to drought.

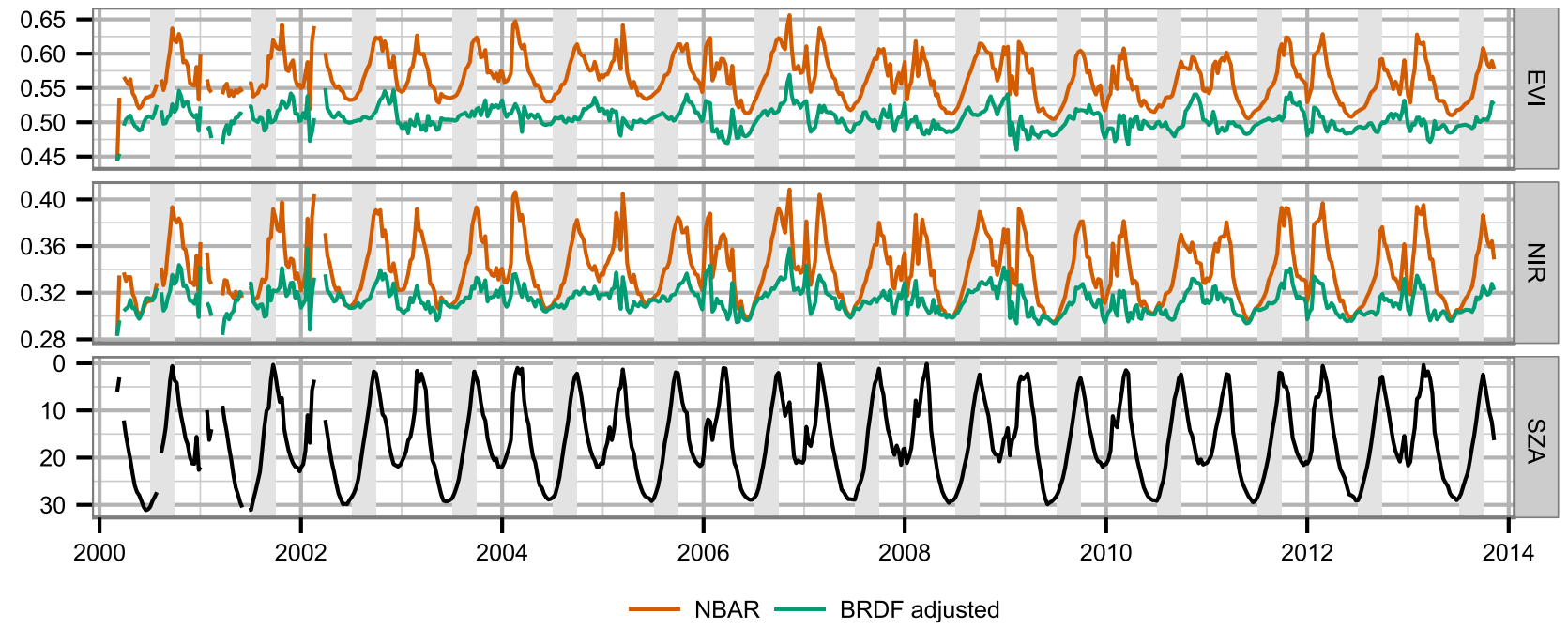

Figure 2: Spatially averaged viewing zenith angle (NBAR) and viewing and sun zenith angle adjusted (BRDF-adjusted, VZA $=0^{\circ}$, $\mathrm{SZA}=30^{\circ}$ ) EVI and NIR for MODIS tiles h11v09 and h12v09, lines connect data points, solar zenith angles are reversed to facilitate comparison with vegetation index trends, 8 day temporal resolution, grey bands indicate typical dry seasons (July to September). 


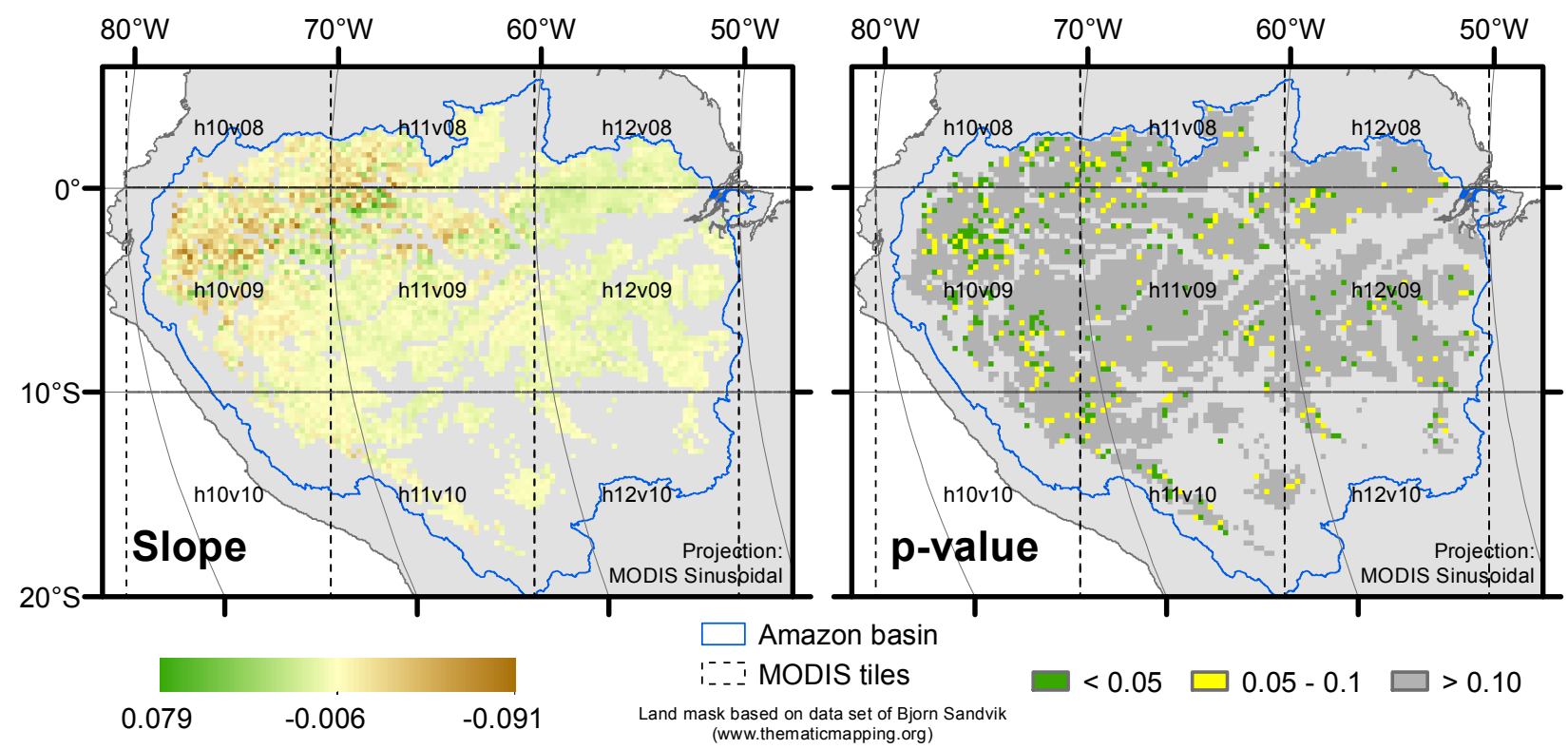

Figure 3: Pixel-based linear regressions of September BRDF-adjusted EVI seasonal anomalies against MCWD on $30 \mathrm{~km}\left(\sim 0.25^{\circ}\right)$ spatial resolution.

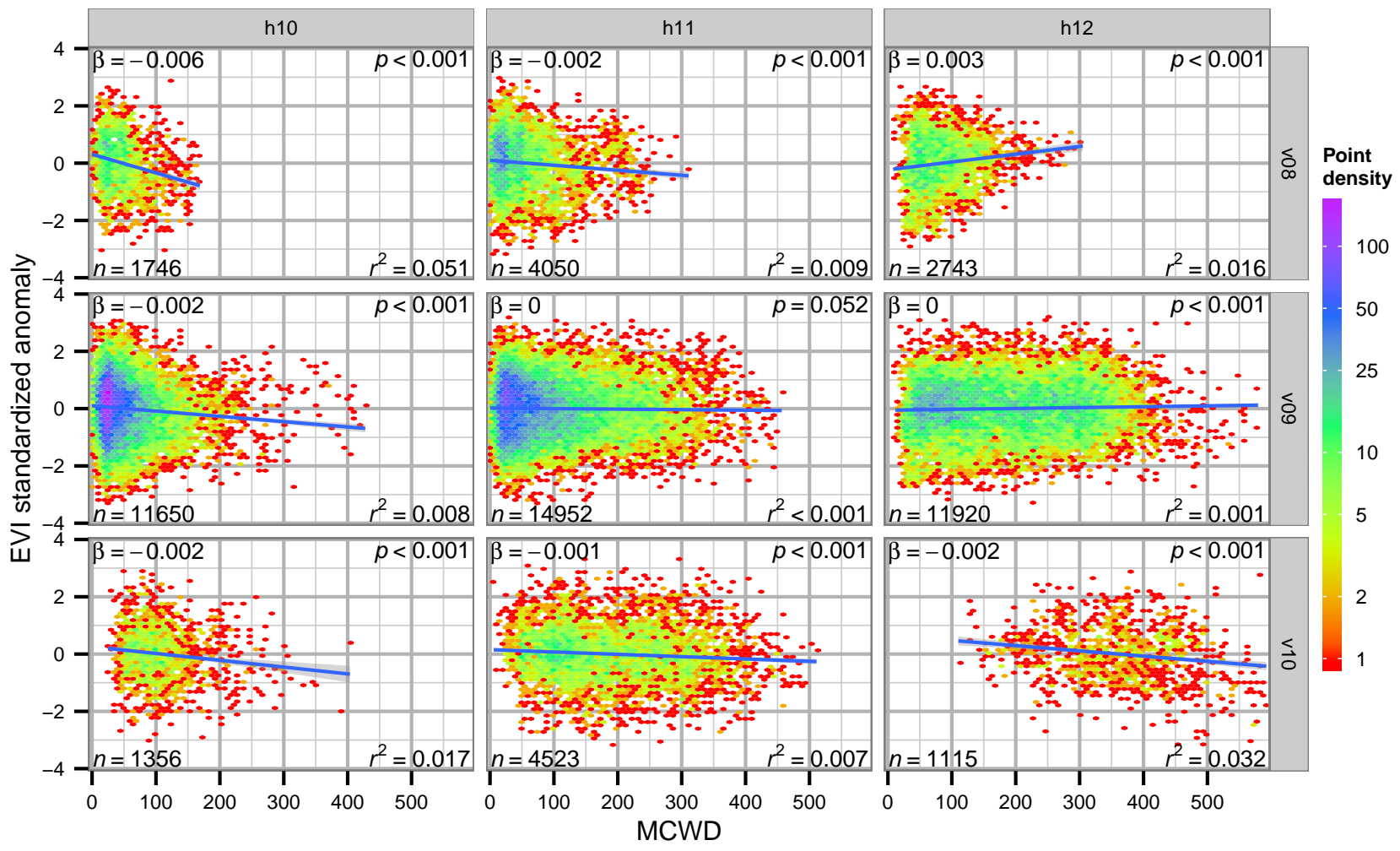

Figure 4: Tile-based scatterplots and regressions of September BRDF-adjusted EVI seasonal anomalies against MCWD, EVI anomalies dimensionless, MCWD in mm, plot grid pattern hints at spatial pattern of MODIS tiles, blue lines are linear regression models, numbers are characteristics of linear models per tile ( $\beta$ is the regression slope), shaded areas are $95 \%$-confidence intervals for regression lines, density color scale is logarithmic. 


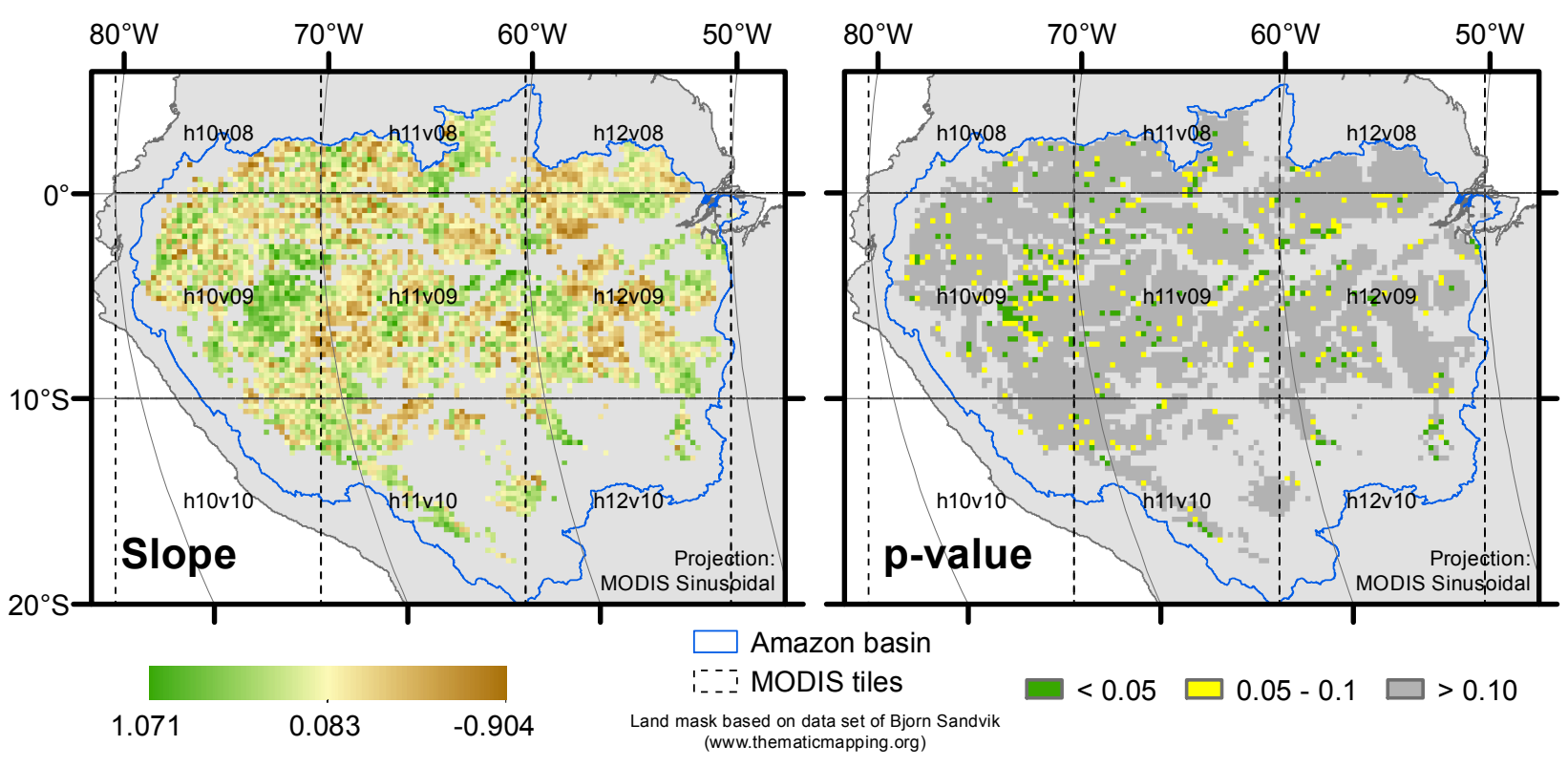

Figure 5: Same as Figure 3, but for SPI.
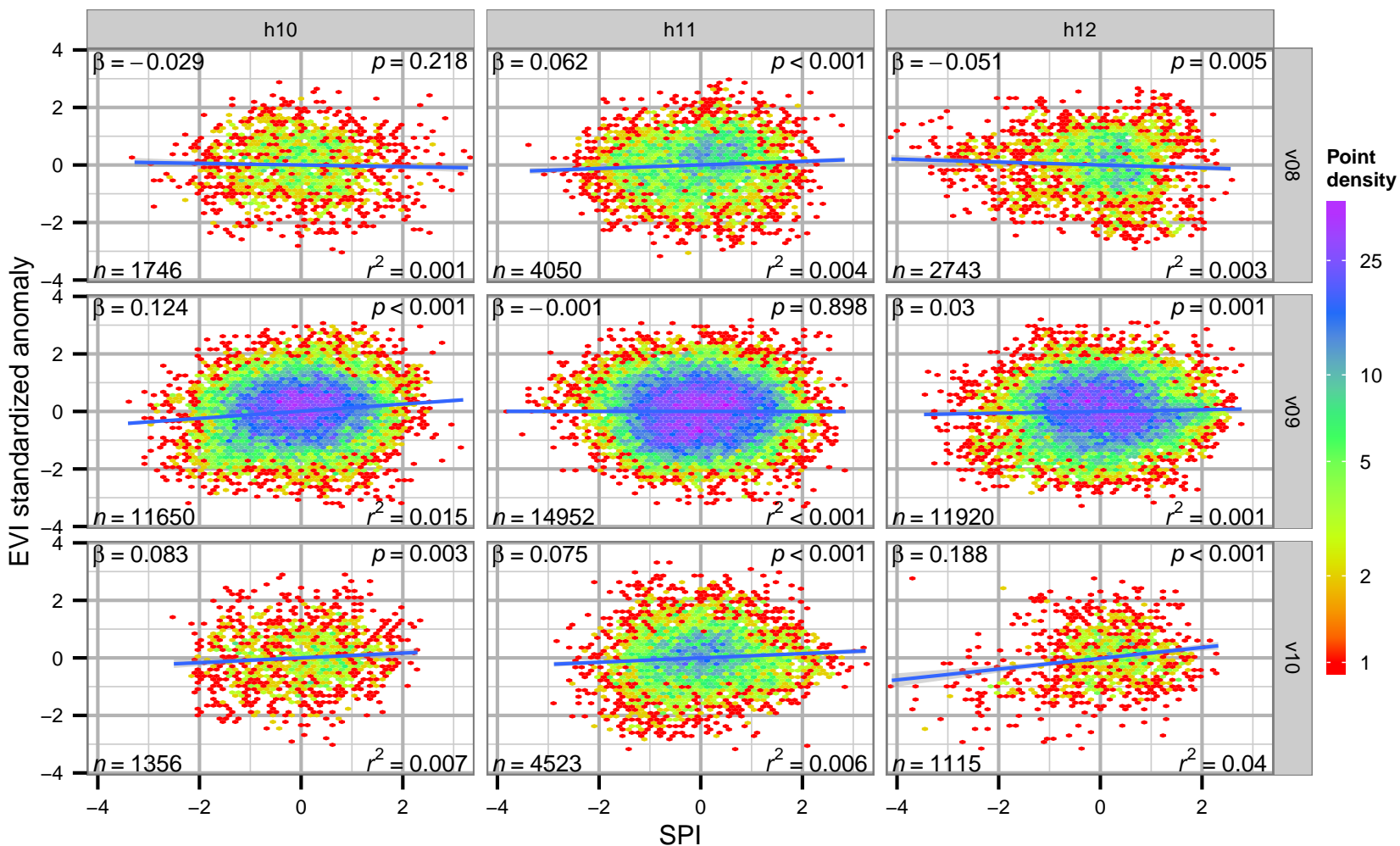

Figure 6: Same as Figure 4, but for SPI. 
Some of these pixel-based regressions were statistically significant $(p<0.1)$. Other positive responding regions were located at the Andean foothills in the South, but no significant relationships could be found for them. This was also true for smaller patches of negative relationships in the eastern basin. Otherwise no broad scale spatial patterns could be identified. The relationship was rather patchy with high variation on short ranges. Additionally, the total number of significant cells at the 0.05 level was $4.1 \%$ of all valid pixels and the histogram of p-values for whole Amazonia showed a nearly uniform distribution. This points to a random process that produced significant slopes only by chance.

All point clouds for the EVI anomaly-SPI relationship were clustered at the point of origin for the respective scatterplots (Figure 6) This is typical for anomalies, as the observations are distributed around the overall mean. The linear models were significant ( $\mathrm{p}<0.01)$ for all tiles but h10v08 and h11v09. However, all models explained less than $5 \%$ of the variance in EVI anomalies expressed as $r^{2}$. Considering the point clouds it becomes clear that any model would have problems to fit the EVI anomaly-SPI relationship.

\section{DISCUSSION}

In this study, we investigated the performance of EVI to study inner-annual dry season and drought impacts on the canopy of undisturbed Amazon forests. We focused on recently discussed sun sensor geometry effects, which contaminate the temporal EVI signals. Correcting for these effects with the MODIS MCD43A1 product, we found distinct seasonal dynamics of EVI. However, these patterns were suspiciously correlated to SZA patterns. Additionally, EVI was not sensitive to canopy moisture stress represented by two moisture stress indices, although droughts have the potential to alter forest canopy functioning (Brando et al., 2008) and structure (Phillips et al., 2010).

From the results the question arises why BRDF-adjusted EVI derived with the MCD43 product suite and EVI derived by Morton et al. (2014) showed different temporal patterns while both products are modeled for the same viewing and sun geometries and cover roughly the same area. This might be explained by the aggregation period for the BRDF modeling approaches. While MCD43 uses 16 day, Morton et al. (2014) used monthly intervals. De Abelleyra and Verón (2014) showed that shorter aggregation intervals result in better noise reduction in NDVI time series for agricultural crops. Taking into account possible rapid changes in Amazon foliage (Doughty and Goulden, 2008), a monthly aggregation period might not take up fast changes, so that EVI time series are overly strong smoothed.

Anomalies of BRDF-adjusted EVI showed no clear response to drought expressed as MCWD and SPI. These results have particular significance, because they were derived on both coarse and medium spatial scales. Moreover, they did not only focus on drought years like 2005 or 2010, but were based on a general assessment over all years when data was available. In this way positive and negative anomalies were assessed in a broader context; chances were lower to interpret spatial or temporal noise in EVI as a response to drought. This can happen if only single drought events are considered for analysis. Furthermore, using seasonal anomalies to analyze EVI sensitivity is robust against seasonal patterns. Anomalies are more robust against seasonal patterns such as viewing and sun geometries and highlight dissimilarities between the years. However, this analysis focused on direct impacts, which occur in the same year as the drought event Impacts on longer time scales as found by Saatchi et al. (2013) were beyond the scope of this study and cannot be excluded.
Moreover, the static evapotranspirational demand of $100 \mathrm{~mm} \mathrm{month}^{-1}$ in the formulation of MCWD is only a coarse approximation that excludes adaptations of trees to drier conditions and the spatial distribution of these adaptations, which is only poorly understood for the Amazon forests (Aragão et al., 2007). This static threshold adds to the explanation for spatial patterns in the NW in Figure 3. These areas lie in the inner Amazon regions and likely experience no water stress, so that the patterns are rather artifacts produced by errors in TMPA retrievals and the assumption of a static evapotranspirational demand.

The question remains why BRDF-adjusted EVI showed no overall sensitivity to the drought indices. On the one hand, this can be caused by a bad representativeness of the drought indices as discussed above. On the other hand, the overall canopy spectral response to drought might be lower than anticipated in earlier studies. For instance, NDVI shows much higher seasonal stability in the study of Samanta et al. (2012). This is usually explained with the saturation of NDVI over dense canopies (Huete et al., 2002). However, NDVI is more robust against sun and viewing angle effects than EVI (Sims et al., 2011). In this sense NDVI might point to the stability of canopy greenness, while EVI is mostly affected by angular effects. Taking into account that drought had fundamental impacts on forest functioning and structure as found in ground studies (Nepstad et al., 2002; Brando et al., 2008), greenness might not be an appropriate proxy for ecosystem functioning in tropical forests.

\section{CONCLUSIONS}

Morton et al. (2014) questioned changes in Amazon rainforest greenness expressed as EVI as a response to dry season and drought conditions. This conclusion was not supported by BRDFadjusted EVI derived with the MODIS MCD43 product. However, seasonal patterns still weakly followed the course of SZA over the year. This might be caused by actual changes in canopy greenness or result from problems in the BRDF modeling process. On the other hand, BRDF-adjusted EVI was mostly insensitive to drought expressed with two drought indices. This could mean that Amazonian forest canopies are resilient against drought impacts. However, studies on forest plots suggest otherwise, so that it is rather EVI's sensitivity for canopy processes that is questionable. Based on these findings, we suggest a careful assessment of EVI as a proxy for tropical rainforest functioning.

\section{References}

Aragão, L. E. O. C., Malhi, Y., Roman-Cuesta, R. M., Saatchi, S., Anderson, L. O. and Shimabukuro, Y. E., 2007. Spatial patterns and fire response of recent Amazonian droughts. Geophysical Research Letters 34(7), pp. L07701.

Brando, P. M., Nepstad, D. C., Davidson, E. A., Trumbore, S. E., Ray, D. and Camargo, P., 2008. Drought effects on litterfall, wood production and belowground carbon cycling in an Amazon forest: results of a throughfall reduction experiment. Philosophical transactions of the Royal Society of London. Series B, Biological sciences 363(1498), pp. 1839-1848.

Cox, P. M., Betts, R. A., Collins, M., Harris, P. P., Huntingford, C. and Jones, C. D., 2004. Amazonian forest dieback under climate-carbon cycle projections for the 21 st century. Theoretical and Applied Climatology 78(1-3), pp. 137-156.

de Abelleyra, D. and Verón, S. R., 2014. Comparison of different BRDF correction methods to generate daily normalized MODIS 250m time series. Remote Sensing of Environment 140, pp. 4659. 
de Toledo, J. J., Magnusson, W. E. and Castilho, C. V., 2013 Competition, exogenous disturbances and senescence shape tree size distribution in tropical forest: Evidence from tree mode of death in Central Amazonia. Journal of Vegetation Science 24(4), pp. 651-663.

Doughty, C. E. and Goulden, M. L., 2008. Seasonal patterns of tropical forest leaf area index and $\mathrm{CO} 2$ exchange. Journal of Geophysical Research 113, pp. G00B06.

Galvão, L. S., dos Santos, J. R., Roberts, D. A., Breunig, F. M., Toomey, M. and de Moura, Y. M., 2011. On intra-annual EVI variability in the dry season of tropical forest: A case study with MODIS and hyperspectral data. Remote Sensing of Environment 115(9), pp. 2350-2359.

Hirota, M., Nobre, C., Oyama, M. D. and Bustamante, M. M. C., 2010. The climatic sensitivity of the forest, savanna and forestsavanna transition in tropical South America. The New Phytologist 187(3), pp. 707-719.

Huete, A., Didan, K., Miura, T., Rodriguez, E., Gao, X. and Ferreira, L., 2002. Overview of the radiometric and biophysical performance of the MODIS vegetation indices. Remote Sensing of Environment 83(1-2), pp. 195-213.

Huete, A. R., Didan, K., Shimabukuro, Y. E., Ratana, P., Saleska, S. R., Hutyra, L. R., Yang, W., Nemani, R. R. and Myneni, R., 2006. Amazon rainforests green-up with sunlight in dry season. Geophysical Research Letters 33(6), pp. L06405.

Huffman, G. J., Adler, R. F., Bolvin, D. T. and Nelkin, E. J., 2010 The TRMM Multi-Satellite Precipitation Analysis (TMPA). In: M. Gebremichael and F. Hossain (eds), Satellite Rainfall Applications for Surface Hydrology, Springer Netherlands, Dordrecht, pp. 3-22.

Hutyra, L. R., Munger, J. W., Saleska, S. R., Gottlieb, E., Daube, B. C., Dunn, A. L., Amaral, D. F., de Camargo, P. B. and Wofsy, S. C., 2007. Seasonal controls on the exchange of carbon and water in an Amazonian rain forest. Journal of Geophysical Research 112(G3), pp. G03008.

Lucht, W., Schaaf, C. and Strahler, A., 2000. An algorithm for the retrieval of albedo from space using semiempirical BRDF models. IEEE Transactions on Geoscience and Remote Sensing 38(2), pp. 977-998.

Malhi, Y., Roberts, J. T., Betts, R. A., Killeen, T. J., Li, W. and Nobre, C. A., 2008. Climate change, deforestation, and the fate of the Amazon. Science 319(5860), pp. 169-172.

Malhi, Y., Wood, D., Baker, T. R., Wright, J., Phillips, O. L., Cochrane, T., Meir, P., Chave, J., Almeida, S., Arroyo, L., Higuchi, N., Killeen, T. J., Laurance, S. G., Laurance, W. F., Lewis, S. L., Monteagudo, A., Neill, D. A., Vargas, P., Nunez Pitman, N. C. A., Quesada, C., Alberto Salomao, R., Silva, J. N. M., Lezama, A. T., Terborgh, J., Martinez, R. and Vasquez Vinceti, B., 2006. The regional variation of aboveground live biomass in old-growth Amazonian forests. Global Change Biology 12(7), pp. 1107-1138.

Mayorga, E., Logsdon, M., Ballester, M. and Richey, J., 2012. BAECO CD-06 Amazon River Basin Land and Stream Drainage Direction Maps. http://dx.doi.org/10.3334/ORNLDAAC/1086.

McKee, T. B., Doesken, N. J. and Kleist, J., 1993. The relationship of drought frequency and duration to time scales. In: Eighth Conference on Applied Climatology, 17-22 January 1993, Anaheim, California, pp. 17-22.

Morton, D. C., Nagol, J., Carabajal, C. C., Rosette, J., Palace, M., Cook, B. D., Vermote, E. F., Harding, D. J. and North, P. R. J., 2014. Amazon forests maintain consistent canopy structure and greenness during the dry season. Nature 506, pp. 221-224.
Moura, Y. M., Galvão, L. S., dos Santos, J. R., Roberts, D. A. and Breunig, F. M., 2012. Use of MISR/Terra data to study intraand inter-annual EVI variations in the dry season of tropical forest. Remote Sensing of Environment 127, pp. 260-270.

Myneni, R. B., Yang, W., Nemani, R. R., Huete, A. R., Dickinson, R. E., Knyazikhin, Y., Didan, K., Fu, R., Negrón Juárez, R. I., Saatchi, S. S., Hashimoto, H., Ichii, K., Shabanov, N. V., Tan, B., Ratana, P., Privette, J. L., Morisette, J. T., Vermote, E. F., Roy, D. P., Wolfe, R. E., Friedl, M. A., Running, S. W., Votava, P., El-Saleous, N., Devadiga, S., Su, Y. and Salomonson, V. V., 2007. Large seasonal swings in leaf area of Amazon rainforests. Proceedings of the National Academy of Sciences of the United States of America 104(12), pp. 4820-4823.

Nepstad, D. C., de Carvalho, C. R., Davidson, E. A., Jipp, P. H., Lefebvre, P. A., Negreiros, G. H., da Silva, E. D., Stone, T. A., Trumbore, S. E. and Vieira, S., 1994. The role of deep roots in the hydrological and carbon cycles of Amazonian forests and pastures. Nature 372(6507), pp. 666-669.

Nepstad, D. C., Moutinho, P., Dias-Filho, M. B., Davidson, E., Cardinot, G., Markewitz, D., Figueiredo, R., Vianna, N., Chambers, J., Ray, D., Guerreiros, J. B., Lefebvre, P., Sternberg, L., Moreira, M., Barros, L., Ishida, F. Y., Tohlver, I., Belk, E., Kalif, K. and Schwalbe, K., 2002. The effects of partial throughfall exclusion on canopy processes, aboveground production, and biogeochemistry of an Amazon forest. Journal of Geophysical Research 107(D20), pp. 8085.

Phillips, O. L., Aragão, L. E. O. C., Lewis, S. L., Fisher, J. B., Lloyd, J., López-González, G., Malhi, Y., Monteagudo, A., Peacock, J., Quesada, C. A., van der Heijden, G., Almeida, S., Amaral, I., Arroyo, L., Aymard, G., Baker, T. R., Bánki, O., Blanc, L., Bonal, D., Brando, P., Chave, J., de Oliveira, A. C. A., Cardozo, N. D., Czimczik, C. I., Feldpausch, T. R., Freitas, M. A., Gloor, E., Higuchi, N., Jiménez, E., Lloyd, G., Meir, P., Mendoza, C., Morel, A., Neill, D. A., Nepstad, D., Patiño, S., Peñuela, M. C., Prieto, A., Ramírez, F., Schwarz, M., Silva, J., Silveira, M., Thomas, A. S., Steege, H. T., Stropp, J., Vásquez, R., Zelazowski, P., Alvarez Dávila, E., Andelman, S., Andrade, A., Chao, K.-j., Erwin, T., Di Fiore, A., Honorio C, E., Keeling, H., Killeen, T. J., Laurance, W. F., Peña Cruz, A., Pitman, N. C. A., Núñez Vargas, P., Ramírez-Angulo, H., Rudas, A., Salamão, R., Silva, N., Terborgh, J. and Torres-Lezama, A., 2009. Drought sensitivity of the Amazon rainforest. Science 323(5919), pp. 1344-1347.

Phillips, O. L., van der Heijden, G., Lewis, S. L., López-González, G., Aragão, L. E. O. C., Lloyd, J., Malhi, Y., Monteagudo, A., Almeida, S., Dávila, E. A., Amaral, I., Andelman, S., Andrade, A., Arroyo, L., Aymard, G., Baker, T. R., Blanc, L., Bonal, D., de Oliveira, A. C. A., Chao, K.-J., Cardozo, N. D., da Costa, L., Feldpausch, T. R., Fisher, J. B., Fyllas, N. M., Freitas, M. A., Galbraith, D., Gloor, E., Higuchi, N., Honorio, E., Jiménez, E., Keeling, H., Killeen, T. J., Lovett, J. C., Meir, P., Mendoza, C., Morel, A., Vargas, P. N. n., Patiño, S., Peh, K. S.-H., Cruz, A. P. n., Prieto, A., Quesada, C. A., Ramírez, F., Ramírez, H., Rudas, A., Salamão, R., Schwarz, M., Silva, J., Silveira, M., Slik, J. W. F., Sonké, B., Thomas, A. S., Stropp, J., Taplin, J. R. D., Vásquez, R. and Vilanova, E., 2010. Drought-mortality relationships for tropical forests. The New Phytologist 187(3), pp. 631-646.

Roujean, J.-L., Leroy, M. and Deschamps, P.-Y., 1992. A bidirectional reflectance model of the Earth's surface for the correction of remote sensing data. Journal of Geophysical Research 97(D18), pp. 20455.

Saatchi, S., Asefi-Najafabady, S., Malhi, Y., Aragão, L. E. O. C., Anderson, L. O., Myneni, R. B. and Nemani, R., 2013. Persistent effects of a severe drought on Amazonian forest canopy. 
Proceedings of the National Academy of Sciences of the United States of America 110(2), pp. 565-570.

Saleska, S. R., Miller, S. D., Matross, D. M., Goulden, M. L., Wofsy, S. C., da Rocha, H. R., de Camargo, P. B., Crill, P., Daube, B. C., de Freitas, H. C., Hutyra, L., Keller, M., Kirchhoff, V., Menton, M., Munger, J. W., Pyle, E. H., Rice, A. H. and Silva, H., 2003. Carbon in Amazon forests: unexpected seasonal fluxes and disturbance-induced losses. Science 302(5650), pp. 1554-1557.

Samanta, A., Knyazikhin, Y., Xu, L., Dickinson, R. E., Fu, R., Costa, M. H., Saatchi, S. S., Nemani, R. R. and Myneni, R. B., 2012. Seasonal changes in leaf area of Amazon forests from leaf flushing and abscission. Journal of Geophysical Research 117(G1), pp. G01015.

Schaaf, C. B., Gao, F., Strahler, A. H., Lucht, W., Li, X., Tsang, T., Strugnell, N. C., Zhang, X., Jin, Y., Muller, J.-P., Lewis, P., Barnsley, M., Hobson, P., Disney, M., Roberts, G., Dunderdale, M., Doll, C., D'Entremont, R. P., Hu, B., Liang, S., Privette, J. L. and Roy, D., 2002. First operational BRDF, albedo nadir reflectance products from MODIS. Remote Sensing of Environment 83(1-2), pp. 135-148.

Schaaf, C. B., Liu, J., Gao, F. and Strahler, A. H., 2011. Aqua and Terra MODIS albedo and reflectance anisotropy products. In: B. Ramachandran, C. O. Justice and M. J. Abrams (eds), Land Remote Sensing and Global Environmental Change NASA's Earth Observing System and the Science of ASTER and MODIS, Springer, New York, Dordrecht, Heidelberg, London, chapter 23, pp. 579-602.

Schwalm, C. R., Williams, C. A., Schaefer, K., Arneth, A., Bonal, D., Buchmann, N., Chen, J., Law, B. E., Lindroth, A., Luyssaert, S., Reichstein, M. and Richardson, A. D., 2010. Assimilation exceeds respiration sensitivity to drought: A FLUXNET synthesis. Global Change Biology 16(2), pp. 657-670.

Sims, D. A., Rahman, A. F., Vermote, E. F. and Jiang, Z., 2011 Seasonal and inter-annual variation in view angle effects on MODIS vegetation indices at three forest sites. Remote Sensing of Environment 115(12), pp. 3112-3120.

Strahler, A. H., Muller, J.-P. and MODIS Science Team Members, 1999. MODIS BRDF/Albedo Product: Algorithm theoretical basis document version 5.0. http://modis.gsfc.nasa.gov/data/atbd/atbd_mod09.pdf.

White, A., Cannell, M. and Friend, A., 1999. Climate change impacts on ecosystems and the terrestrial carbon sink: A new assessment. Global Environmental Change 9, pp. S21-S30.

Xiao, X., Hagen, S., Zhang, Q., Keller, M. and Moore, B., 2006. Detecting leaf phenology of seasonally moist tropical forests in South America with multi-temporal MODIS images. Remote Sensing of Environment 103(4), pp. 465-473. 